\title{
La moderación judicial como legado constitucional autoritario: el Supremo Tribunal Federal brasilero y las facultades legislativas presidenciales
}

\author{
Judicial restraint as an authoritarian constitutional \\ legacy: the Brazilian Supreme Court and presidential \\ lawmaking powers ${ }^{\circ}$
}

Diego Werneck Arguelhes*

Resumen: Durante la transición democrática de los 90, el Supremo Tribunal Federal brasilero ("STF") fue significativamente moderado en la interpretación e implementación de poderes que la nueva Constitución le había otorgado, particularmente en relación con la cuestión de las facultades legislativas presidenciales. La nueva Constitución creó un mecanismo limitado para la legislación presidencial (medidas provisórias), sujeto a distintos tipos de control de constitucionalidad. Sin embargo, el STF limitó y moderó estos nuevos controles de varias maneras, adoptando en general una postura pasiva. Si bien en un contexto de consolidación democrática y desde una perspectiva estratégica

- Traducción del inglés de Ianina Moretti. Revista Discusiones agradece a Sebastián Elías, Paula Gaido y Rodrigo Sánchez Brígido, anteriores editores de la sección Dicusiones Cortes, por la gestión de la presente contribución.

J.S.D., LL.M., Yale Law School. LL.B., M.A., Universidade do Estado do Rio de Janeiro, Brasil. Professor Associado del Insper - Instituto de Ensino e Pesquisa-, São Paulo, Brasil. Correo electrónico: diegowa@insper.edu.br. El autor agradece a Evandro Süssekind y a un referí anónimo por sus comentarios a versiones previas de este texto; a Mariana Muniz, por la edición y la asistencia en la investigación; y a Ivar Hartmann y Guilherme Almeida por facilitar los datos provenientes del proyecto Supremo em Números de la FGV Direito Rio. 
estas muestras de moderación judicial no serían extrañas, en este artículo uso el caso brasilero para mostrar la influencia de otro tipo de variable: concepciones jurídicas preconstitucionales sobre el alcance de la decisión judicial. Tales concepciones pueden influir en el comportamiento judicial más allá de los cálculos estratégicos, en tanto que pueden expresar y moldear creencias sinceras de los jueces acerca del rol apropiado de su institución en relación con los otros poderes. El caso brasilero muestra que el legado de creencias judiciales tradicionales puede triunfar incluso sobre nuevos textos constitucionales - aun cuando estos textos otorgan a las cortes claras facultades para controlar otras ramas del gobierno-, moldeando así de forma perdurable la separación de poderes. Palabras clave: Cambio constitucional, transición democrática, separación de poderes, facultades legislativas presidenciales, Supremo Tribunal Federal brasilero.

Abstract: In the aftermath of the transition to democracy in the 90s, the Brazilian Supreme Court (STF) displayed significant restraint in how it interpreted and deployed the powers it had been granted by the new constitution. This was particularly true on the issue of presidential legislative powers. The new constitution created a limited mechanism for presidential law-making (medidas provisórias, or "provisional measures"), subjecting this new power to different kinds of legislative and judicial checks. In the 90s, however, the STF restricted these new checks in many ways, adopting a generally passive stance. While such displays of judicial restraint in consolidating democracies are unsurprising from a strategic behavior perspective, in this paper I use the Brazilian case to show the influence of a different kind of variable: pre-constitutional legal understandings on the proper scope of judicial decision-making. Such legal understandings can influence judicial behavior beyond strategic calculations, insofar as they can express and shape sincerely held judicial beliefs on the appropriate role of their institution vis-à-vis the other branches. The Brazilian case shows that the legacy of traditional judicial beliefs can trump even new constitutional texts - even when these texts clearly empower courts to check other branches of government -, shaping separation of powers in lasting ways. Keywords: Constitutional change, transition to democracy, separation of powers, presidential law-making powers, Brazilian Supreme Court. 
La moderación judicial como legado constitucional autoritario: el Supremo...

\section{Introducción}

Desde hace ya muchos años, el Supremo Tribunal Federal brasilero (“STF”) ha sido muy poco moderado en su abordaje de la separación de poderes. Al decidir, por ejemplo, que la Constitución prohíbe que los legisladores autoricen aportes de campaña por parte de personas jurídicas tales como empresas privadas, el Tribunal ha directamente moldeado el proceso electoral y el sistema político. ${ }^{1}$ También ha transformado, de muchas maneras, el funcionamiento de la administración pública en todas las esferas de la federación brasilera; por ejemplo, al establecer la prohibición del nepotismo en la mayoría de los nombramientos políticos, vinculante para los tres poderes del gobierno. ${ }^{2}$ También se ha mostrado regularmente anuente con decisiones de tribunales inferiores que exigían a gobiernos locales dar acceso a remedios específicos a individuos específicos, o a construir guarderías $^{3}$. Lo que es más, el Tribunal ha moldeado ampliamente los procedimientos del Congreso durante los juicios de destitución de los presidentes Collor (1992) y Rousseff (2015-2016). En relación con la decisión de casos que involucran condiciones infrahumanas de las prisiones, los jueces han afirmado que la idea de la "separación de poderes" no puede impedir el control de constitucionalidad en los casos en los que hay una potencial violación de la Constitución. ${ }^{4}$

Se sabe que el STF otorga poderes expansivos a sus jueces individuales, a fin de realizar el control de constitucionalidad sin necesariamente consultar con el resto de la corte. De todos modos, los ejemplos antes mencionados son fallos colectivos, tomados por la corte en su conjunto. ${ }^{5}$ Se encuentran en marcado contraste con la perspectiva general del STF durante los años 90. Durante la década posterior a la promulgación de la nueva constitución en 1988, el STF fue o bien cautelosamente prudente y moderado,

1 Véase ADI 4650.

2 Véase ADC 12 y RE 579951.

3 Véase Rosevear (2018) para una discusión general de la jurisprudencia de la Corte; véase también Vasconcelos (2020).

4 Véase, por ejemplo, RE 592581.

5 Para una discusión sobre el modo en que el STF asigna prerrogativas para la toma de decisiones y otras facultades a sus jueces individuales, véase Arguelhes y Ribeiro (2018).

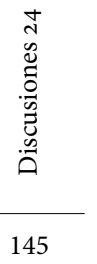


o bien rotundamente deferente para con el Ejecutivo - una corte que no podría ser considerada "activista", bajo ningún punto de vista-.${ }^{6}$ Se sabe que durante los procesos de consolidación democrática, las cortes han estratégicamente evitado tomar decisiones que pudieran provocar represalias por parte de los otros poderes (Ginsburg, 2003). Sin embargo, el caso brasilero tiene una característica distintiva. El texto original de la Constitución de 1988 fue particularmente explícito respecto de los poderes otorgados al STF.7 Los constituyentes, los académicos, la comunidad jurídica, los políticos y los activistas parecían estar todos de acuerdo en relación con el rol prominente de lo judicial en la democracia brasilera naciente. Se podría decir que la posición altamente moderada del STF en los años 90 fue adoptada contra legem, una corte que deliberadamente interpretó la nueva Constitución de forma tal que terminó diluyendo o ignorando varias cláusulas que podrían haber otorgado a los jueces poderes suficientes para actuar como revisores de las acciones gubernamentales. ${ }^{8}$

En este artículo, discuto un aspecto del proceso de transformación entre estos dos escenarios, de la (relativa) moderación judicial de los años 90 a la (relativa) voluntad de interferir en dominios del poder político. Atendiendo a cómo interpretó el STF postransicional el nuevo texto constitucional sobre las facultades legislativas asignadas al poder Ejecutivo, podemos ver cómo la moderación judicial observada en los años 90 tenía apoyos legales inconfundibles. El STF leyó las nuevas cláusulas constitucionales recurriendo a viejas decisiones, que habían sido tomadas durante la dictadura y que por ello eran mucho menos amigables respecto de la posibilidad que los jueces o el Congreso revisaran la legislación creada por el ejecutivo. Los jueces interpretaron las normas estructurantes de la relación entre poderes de manera similar al orden constitucional autoritario previo, que era mucho más hostil a la revisión judicial y a la supervisión del Congreso en cuanto a legislación del ejecutivo. Al hacerlo, crearon un

6 Compárese, por ejemplo, Kapiszewsk (2011); Brinks (2011).

7 Véase, por ejemplo, Arantes (1997).

8 Para un desarrollo de este argumento en varias áreas del derecho, y especialmente en relación con el diseño del control de constitucionalidad, véase Arguelhes y Prado (2019). 
La moderación judicial como legado constitucional autoritario: el Supremo...

espacio "legal" seguro para que la Corte pudiera mantenerse al margen del Ejecutivo.

Este estudio jurisprudencial tiene implicancias para nuestra comprensión del comportamiento de cortes postransicionales. Los estudios sobre cortes en las nuevas democracias que intentan explicar las elecciones hechas por los jueces en casos de alto perfil sobre separación de poderes y su postura general frente al poder ejecutivo han tendido a enfatizar el comportamiento estratégico. ${ }^{9}$ El elemento clave de mi explicación es el rol de las preferencias sinceras de los jueces sobre los límites de la función judicial. Estas preferencias judiciales no están en relación con políticas específicas, sino más bien con un arreglo específico de separación de poderes. Ellas pueden dar forma al diseño institucional más allá de los casos específicos (Arguelhes y Süssekind, 2018). En este sentido, el STF no solo estaba decidiendo si y cómo usar los poderes que le había garantizado la nueva constitución. Antes bien, esa primera generación de jueces del STF estaba realizándose la pregunta más amplia sobre cuáles poderes debería tener su Corte en primer lugar. Contestaron esta pregunta recurriendo a decisiones judiciales pretransicionales, que desplegaron para justificar su rol moderado postransicional. Aunque esas teorías preconstitucionales chocaban con el nuevo texto constitucional en muchas maneras, proveyeron de justificación y protección legal suficiente al retraimiento judicial, frente al poder presidencial.

\section{Cortes postransicionales: ¿̇redención o prudencia?}

Mientras que las facultades legislativas presidenciales son una característica frecuente de los sistemas presidenciales contemporáneos, el constitucionalismo latinoamericano se caracteriza en particular por diseños que otorgan grandes poderes al titular del poder ejecutivo (Cheibub, Elkins y Ginsburg,

9 Hay excepciones. Para un ejemplo de un abordaje más detallado que compara Argentina y Brasil, véase Kapiszewski (2012); para un análisis del comportamiento de Tribunal Constitucional chileno en el tiempo, incorporando creencias judiciales sobre su rol profesional, véase Couso y Hilbink (2011). 
2011). ${ }^{10}$ A partir del siglo XIX, el derecho constitucional de la región ha incorporado lo que Loveman denomina "regímenes de excepción": disposiciones o convenciones constitucionales que, en cuanto se activan por circunstancias políticas “excepcionales", permiten que los poderes estatales sean aumentados y redistribuidos entre los poderes del gobierno, típicamente concentrándolos en el ejecutivo (Loveman, 1993). ${ }^{11}$ Aunque inicialmente se concebían en términos de autoridad expandida para suprimir rebeliones $\mathrm{u}$ otras amenazas para la existencia de la comunidad, alrededor del siglo XX, la expresión constitucional de aquellas ideas cambió gradualmente desde medidas represivas específicas, dirigidas a eventos políticos específicos e individuos, hacia facultades legislativas más amplias dentro del proceso legislativo mismo. La participación judicial en el diálogo sobre si y cómo estas disposiciones de "crisis" podrían activarse, tendía a ser extremadamente limitada; el poder ejecutivo era quien debía decidir esas cuestiones.

Estudiosos constitucionalistas han predicho que, con posterioridad a un cambio de régimen hacia la democracia, las cortes tenderían a sentirse más cómodas con intervenir en decisiones del poder político. Es bien conocido el argumento de Ackerman de los 90: diferentes escenarios fundacionales pueden ayudar a explicar distintos modelos de comportamiento de una corte constitucional con posterioridad a un cambio de régimen. Desde su punto de vista, un "nuevo comienzo constitucional" es un escenario en el cual una nueva constitución "emerge como marca simbólica de una gran transición en la vida de una nación” (Ackerman, 1997, p. 778). Una vez que una constitución alcanza este estatus simbólico, afecta la "subsecuente batalla judicial por la autoridad política" al proveer "capital simbólico" para las cortes. Según Ackerman, con el paso del tiempo, la legitimidad de la generación revolucionaria comienza a disiparse y a devenir en burocratización, y el "carisma" que antes atraía a los "verdaderos creyentes" puede en cambio ser transferido a una constitución nueva, que consagre los principios del nuevo régimen. En este "escenario triunfalista", la nueva

${ }^{10}$ Véase también Gargarella (2013).

11 Loveman no discute el caso brasilero, pero las disposiciones de la Constitución argentina de 1953 sobre el estado de sitio, que el autor analiza en el libro, fueron fuente de inspiración y de trasplante explícito para los redactores de la Constitución brasilera de 1891. Véase Lynch (2012). 
La moderación judicial como legado constitucional autoritario: el Supremo...

corte puede explotar (y lo hará) el alineamiento entre el nuevo régimen y la nueva constitución. En cuanto los jueces se presenten exitosamente a sí mismos como quienes hablan por el "nuevo comienzo constitucional", tendrán poderes otorgados por la nueva constitución, y serán capaces de interactuar más agresivamente con las otras ramas del gobierno.

¿Ha sido este el caso de Brasil? Tal como se expuso anteriormente, durante la década posterior a la transición a la democracia, el STF fue considerado demasiado cuidadoso respecto de interferir con decisiones políticas. Suponiendo que la Constitución de 1988 pudiera ser presentada como la que estableciera un "nuevo comienzo constitucional", trazando la línea entre dictadura y democracia, ¿por qué los jueces postransicionales rechazarían el abordaje "de la redención" descrito por Ackerman? ¿Por qué motivo esos jueces - que habían sido tan explícita y recientemente dotados de poderes por la nueva constitución - habrían elegido el camino de la prudencia y la moderación, en lugar de reclamar para su institución un rol más central en el nuevo escenario político? Considérese la figura 1, debajo. El gráfico muestra,

Figura 1: \% de fallos favorables al demandante - demandas de control abstracto de constitucionalidad (ADIs), 1990-2019.

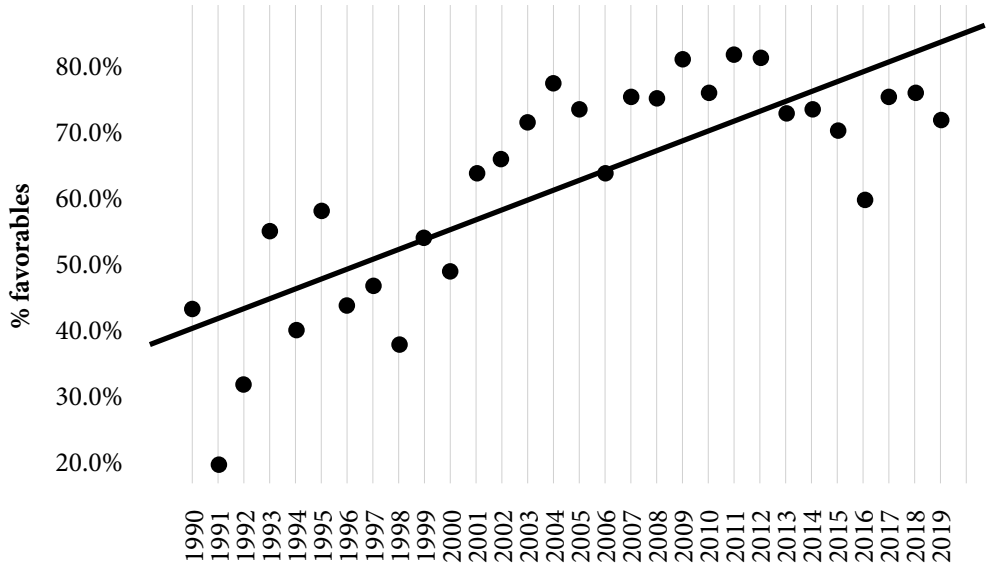

Año (decisión) 
en el tiempo, el porcentaje de decisiones sobre el fondo, en un tipo específico de procedimiento de control abstracto de constitucionalidad (Ações Diretas de Inconstitucionalidade, o "ADIs"), en las cuales el STF ha accedido, al menos parcialmente, al cuestionamiento de la constitucionalidad de la ley.

El escenario representado por los datos es muy diferente al de la narrativa del "nuevo comienzo". En sus primeros años de lidiar con la nueva constitución, el STF fue claramente reticente en el ejercicio de sus poderes. La corte devino cada vez más agresiva con el tiempo (al menos según la medida de cuán dispuesta estaba a hacer una revisión constitucional) en tanto se iba alejando de la "zona cero" de la transición a la democracia. El comportamiento del STF, sin embargo, está en sintonía con la predicción de los estudios de cortes postransicionales que enfatizan la toma de decisiones estratégica por parte de jueces de tribunales superiores. Tal como ha observado Ginsburg (2003, capítulo 3), en el contexto de una consolidación democrática, los costos del incumplimiento de las decisiones judiciales siguen siendo limitados. Mientras que el resto de las variables permanezcan constantes, son las decisiones judiciales contra el gobierno en funciones las más propensas a inducir represalias, si se toman luego de la transición, y no tiempo después. Ya que los jueces de cortes constitucionales están al tanto del ambiente político en que operan sus instituciones (y responden a este), anticipan la probabilidad de represalias por parte de actores políticos y modulan su conducta de acuerdo con ello.

El elemento de la conducta estratégica es ciertamente importante para comprender el caso brasilero. Aun así, provee una imagen incompleta. Considérese que la Figura 1 muestra al STF moderado incluso en su abordaje de leyes promulgadas por el régimen saliente. Incluso si esos jueces estuvieran considerando estratégicamente los peligros para su institución, al considerar políticas del gobierno involucrado en los comienzos del nuevo régimen, ¿por qué incluirían en su moderación decisiones políticas hechas por el régimen anterior? ¿Por qué se negarían a declarar como inconstitucionales incluso leyes y regulaciones promulgadas durante la dictadura? ¿Es entonces la conducta estratégica la única explicación posible para la moderación postransicional del STF?

En la siguiente sección, ofreceré una explicación alternativa, no excluyente, para la postura moderada incluso en relación con las decisiones 
La moderación judicial como legado constitucional autoritario: el Supremo...

políticas hechas antes del comienzo de la democracia. Los jueces del STF postransicional tenían ciertas concepciones legales acerca del alcance adecuado del poder ejecutivo y los posibles mecanismos para controlarlo, incluyendo controles de constitucionalidad. Tales concepciones se habían consagrado en decisiones tomadas por el STF durante la dictadura, pero no fueron abandonadas después de la transición. Más allá de comprender cómo el STF usó sus poderes en los 90, entonces, necesitamos atender los modos en que diferentes generaciones de jueces dieron forma a las concepciones existentes sobre el rol judicial a lo largo del tiempo, durante y después de la transición a la democracia, y cómo esos legados moldearon decisiones durante el nuevo régimen.

\section{Legislación presidencial en la Constitución de 1988}

Reestructurar el sistema de gobierno era una de las cuestiones claves en la agenda de la Asamblea Nacional Constituyente ("ANC"), convocada en febrero de 1987. Se consideró que la estabilidad política y económica del país estaba directamente relacionada con las decisiones institucionales fundamentales que se debían tomar (Limongi, 2008, p. 23). Respecto al sistema de gobierno, el objetivo principal fue rediseñar la relación entre el poder ejecutivo y los demás poderes, para asegurar que el gobierno sea a la vez efectivo y democráticamente responsable. En la ANC hubo amplio apoyo a la idea de que las facultades legislativas del ejecutivo no deberían ser completamente eliminadas, sino antes bien, moderadas y sujetas a control. ${ }^{12} \mathrm{Al}$ diseñar mecanismos para este propósito, los constituyentes tenían dos ejemplos negativos en mente. El primero proveniente del orden constitucional autoritario previo. Las Constituciones de 1967 y 1969 consagraron muchas esferas de legislación presidencial no supervisada. Aunque el Congreso Nacional tenía un rol tenue y complejo en la dictadura militar,

12 Power (1998, p. 201) afirma que "ni una persona o facción de la ANC defendía el sostenimiento del tan despreciado decreto-ley (...) Pero varios legisladores estaban preocupados de que fuese insensato privar a la cabeza del gobierno brasilero de toda y cualquier facultad extraordinaria". 
no tenía influencia significativa en el proceso legislativo. La iniciativa presidencial era necesaria y suficiente para la promulgación de leyes válidas - un claro ejemplo de lo que Carlos Santiago Nino describiera como un "hiper-presidencialismo" (Nino, 1992)-.

El segundo ejemplo negativo era la Constitución democrática de 1946. Los redactores de aquella Constitución habían expandido enormemente el poder de los miembros individuales del Congreso en relación con el presidente, precisamente porque tenían la Constitución dictatorial del Estado Novo de 1937, centrada en el Ejecutivo, como su propio ejemplo negativo. En el sistema político de 1946, con listas abiertas con representación proporcional, y poca o ninguna disciplina partidaria, era difícil distinguir entre gobierno y oposición, y el presidente tenía poco poder constitucional para controlar la agenda legislativa (Santos, 2003). Tal sistema podía crear una "pesadilla Linziana", en la cual un presidente electo sin facultades legislativas se encontraba con herramientas para tratar con un Congreso paralizado o inactivo (Ackerman, 2000). La crítica pública de ese diseño constitucional de un "Congreso amorfo" en conflicto con "un presidente plebiscitario" había estado en discusión desde fines de la década de 1940 y era parte explícita de una agenda consensuada cuando la ANC se reuniera en 1987 (Ackerman, 2000 y Limongi, 2008).

Estos dos ejemplos admonitorios —las Constituciones de 1946 y 1967 están en tensión. Uno recomienda otorgar poderes al presidente dentro del proceso legislativo, de modo que se reduzcan los incentivos para llevar a cabo acciones extraconstitucionales en caso de estancamiento legislativo. El otro, en cambio, enfatiza los peligros de las facultades legislativas presidenciales excesivas. Navegando entre estos dos ejemplos negativos, la tarea de la Asamblea de contrarrestar el dominio presidencial por sobre el proceso legislativo nunca podría llegar a directamente despojar a la presidencia de sus facultades legislativas. De hecho, durante todas las fases del proceso de redacción constitucional, hubo cláusulas que otorgaban un conjunto sustancial de tales poderes. ${ }^{13}$ El objetivo era otorgar facultades legislativas al presidente, que no impidieran al Congreso ser un jugador decisivo en el proceso legislativo.

${ }^{13}$ Desde el comienzo, los defensores de ambos sistemas de gobierno acordaron que la rama del ejecutivo debería tener un rol decisivo y activo en el proceso legislativo, aun si la cues- 
La moderación judicial como legado constitucional autoritario: el Supremo...

La solución que eventualmente encontró su lugar en la Constitución de 1988 consistió en dotar al presidente con medios legales para superar la inacción del Congreso, mientras que forzaba al Congreso a tomar una postura -cualquier postura excepto mantenerse en silencio- acerca de estas iniciativas presidenciales. El presidente debería poder ser capaz de hacer el primer movimiento y cambiar el status quo legal, mientras que el Congreso conservaba el poder de rechazarlos ex post. Así, la Constitución de 1988 otorgaba al poder ejecutivo "rutas de escape [...] cuando un desacuerdo potencial entre los poderes pudiera llevar a una confrontación abierta o a la inacción" (Limongi, 2008, pp. 25-26). ${ }^{14}$

En este sentido, la Constitución le dio al presidente el poder de promulgar medidas provisórias ("medidas provisorias"). De acuerdo con la redacción original del artículo 62 de la Constitución, en casos de "urgencia e interés público relevante", el presidente puede adoptar inmediatamente "medidas provisorias" con "fuerza de ley". Tales medidas serían inmediatamente sometidas a escrutinio y aprobación del Congreso, pero devienen legalmente vinculantes tan pronto como se promulgan. ${ }^{15}$ Sin embargo, a diferencia de los decretos-lei que eran el motor del dominio presidencial en las Constituciones autoritarias de 1937 y 1967, las medidas tienen una fecha de vencimiento. Si, después de 30 días, el Congreso no hubiera decidido sobre el fondo de una medida provisoria, la misma expiraría y cesaría de tener cualesquiera otros efectos.

tión sobre si el país debería seguir siendo presidencialista o devenir en un sistema parlamentario/semipresidencial solo sería saldada después de dos años de debate. Fernando Limongi (2008, p. 25): “Los dos bandos — presidencialistas y parlamentaristas — abogaban por darle al poder ejecutivo los medios necesarios para producir decisiones y que la condición sine qua non para ello era la 'modernización' de la legislatura, para prevenir que se transforme en un obstáculo para el funcionamiento armonioso del gobierno".

${ }^{14}$ Véase también Pilatti (1999), quien señala "los constituyentes de 1987-1988 tenían en desafío de volver a establecer las prerrogativas del Congreso en el proceso legislativo sin privar al poder ejecutivo de instrumentos legislativos".

${ }^{15}$ Los decretos del Poder Ejecutivo que tienen la misma fuerza de ley que las leyes son una característica de muchos países presidenciales con sistemas de derecho civil. Para un panorama general, véase Carey y Shugart (1998). No deberían confundirse con las medidas tomadas por el Ejecutivo para detallar, implementar y/o ejecutar leyes que ya han sido promulgadas. 
Las facultades legislativas presidenciales están ampliamente difundidas en los sistemas políticos actuales de Latinoamérica. ${ }^{16}$ En Brasil, por ejemplo, desde los comienzos de 1990, el proceso político ha sido ampliamente dominado por el presidente, cuyas propuestas legislativas son generalmente exitosas y representan una gran porción de la producción legislativa. ${ }^{17} \mathrm{Sin}$ embargo, incluso si la mayoría de dicha producción legislativa puede rastrearse hacia la iniciativa presidencial, esto no necesariamente significa que todas las leyes serán un reflejo perfecto de preferencias presidenciales incontroladas. Las facultades legislativas presidenciales no deberían implicar un dominio presidencial completo por sobre el contenido de la legislación.

Para asegurar que habría controles efectivos sobre la capacidad del presidente para dar forma unilateral al contenido de esas leyes, la ANC adoptó algunas estrategias institucionales. Primero, expandió ampliamente el acceso a la jurisdicción de control abstracto de constitucionalidad del Supremo Tribunal. En 1890, Brasil había adoptado una revisión en concreto de la legislación, estilo EE. UU.; en 1965, la dictadura militar aprobó una enmienda constitucional que permitía que el fiscal general presentara demandas de control abstracto de constitucionalidad directamente ante la Corte. Este modo tradicional de control de constitucionalidad es "impulsado por apelación”; los casos concretos deben hacerse paso a través de cortes inferiores antes que el STF tenga la oportunidad de dictaminar sobre la cuestión constitucional subyacente - si es que estos casos llegaran al STF-. En cambio, las nuevas demandas de control abstracto de constitucionalidad permitían un gran despliegue de actores políticos e institucionales -incluyendo cualquier partido político con al menos una banca en el Congreso que podía inmediata y directamente impugnar leyes específicas ante la Corte Suprema- ${ }^{18}$ En la práctica, esto aseguraba que cualquier medida provisória mínimamente controversial encontraría rápidamente su camino hacia la lista de casos pendientes del STF.

\footnotetext{
${ }^{16}$ Véase Carey y Shugart (1992). Para América Latina, véase Cheibub, Elkins y Ginsburg (2011).

17 Véase Melo y Pereira (2013).

18 Para una exploración de los diferentes incentivos que estos dos modos de control crean para la Corte Suprema, véase Ferreres Comella (2003).
} 
La moderación judicial como legado constitucional autoritario: el Supremo...

Segundo, el nuevo texto constitucional forzaba al Congreso a compartir responsabilidad por el destino de cada medida provisória. En el sistema de 1967, el paso del tiempo favorecía siempre al presidente, cuyas leyes-decreto serían tratadas como si el Congreso hubiera tácitamente consentido a su promulgación. El Congreso llevaba así toda la carga de sus estancamientos internos. En el sistema de 1988, después de 30 días, una medida provisória dejaba de ser vinculante. Entonces, aunque los presidentes tuviesen aún ventaja al negociar con el Congreso (dado su poder de inmediatamente cambiar el status quo), también tendrían incentivos para obtener alguna decisión del Congreso. Esperar pasivamente a que transcurriera el tiempo no sería ya una opción. Así, se esperaba que la fecha de vencimiento de las medidas provisórias funcionaran como un dispositivo de fomento del diálogo (Abramovay, 2011).

\section{Legislación presidencial, interpretación judicial y legados constitucionales}

A pesar de sus fallas, claramente el mecanismo de medida provisória no es un diseño para la absoluta discrecionalidad presidencial. El considerable poder del presidente está bajo control judicial y del Congreso. Y, si el Congreso permaneciera callado, la medida provisória perdería su fuerza legal. Sería de interés presidencial, entonces, lograr que el Congreso delibere sobre una medida dada. ${ }^{19}$ Este intrincado arreglo era la traducción constitucional de un consenso político sobre cómo los viejos arreglos de separación de poderes debían ser transformados. Sin embargo, a pesar de este consenso político o de las instituciones que se crearon, los arreglos de separación de poderes del nuevo régimen terminaron pareciéndose en la práctica al viejo orden constitucional. El STF postransicional jugó un rol central en este escenario, manteniendo vivos aspectos clave del viejo orden

19 Según Argelina Figueiredo y Fernando Limongi (1999, pp. 132-133): “El revés de los efectos del plazo tenía el objetivo de asegurar la participación efectiva del Congreso en el proceso legislativo, mientras que al mismo tiempo desalentaba al ejecutivo de recurrir a decretos. Dada la duración limitada del decreto, cuando usaba este poder, el ejecutivo hubiera tenido 
constitucional que restringían enormemente el alcance de la revisión judicial y del Congreso sobre la producción legislativa presidencial.

\subsection{El orden constitucional pretransicional}

La existencia de ámbitos de poder presidencial absolutamente discrecional fue un rasgo central del régimen legal militar. Los presidentes tenían el poder de: (i) promulgar decretos, con fuerza de ley, en materia de seguridad nacional y finanzas públicas; ${ }^{20}$ (ii) enviar proyectos de ley y enmiendas constitucionales al Congreso, y transformarlos en ley si no eran votados por ambas cámaras en un período corto de tiempo - el mecanismo denominado "decurso de prazo" - ; ${ }^{21}$ (iii) el poder de legislar libremente sobre cualquier cuestión siempre que el Congreso estuviera en receso. ${ }^{22}$ Lo que es más, aunque Brasil tenía un estilo norteamericano de sistema de control de constitucionalidad ya desde 1891, la legislación extraconstitucional —los “Atos Institucionais" o "Actos Institucionales" - solían contener cláusulas que ubicaban estas leyes y medidas excepcionales más allá del ámbito de dicho control.

La "matriz autoritaria" que moldeaba estos ámbitos de discrecionalidad inapelable era más amplia que el texto constitucional y que los atos institucionais (Pereira, 2005). En muchas instancias, al interpretar y aplicar esos textos legales, el STF agrandaba el espectro de los ya extensos ámbitos de discreción presidencial. Los juristas han observado que el Superior Tribunal desplegaba una independencia considerable al decidir casos penales específicos. ${ }^{23}$ Cuando el STF debía decidir cuestiones estructurales y arbi-

que actuar sobre las bases de un estimado de las probabilidades de obtener la aprobación del Congreso a tiempo. Promulgar un gran número de decretos podría poner en peligro las posibilidades del propio gobierno de asegurar su aprobación en el Congreso. En este escenario, este poder estaría reservado a medidas verdaderamente extraordinarias, sobre las cuales el ejecutivo estuviese seguro de contar con apoyo político".

20 Artículo 54 de la Constitución de 1967.

${ }^{21}$ Véase artículo 54 de la Constitución de 1967.

22 Véase Ato Institucional n.5 ("AI-5"), promulgado en diciembre de 1968.

${ }^{23}$ Para una discusión reciente de estudios académicos relevantes, véase Carvalho (2017). 
La moderación judicial como legado constitucional autoritario: el Supremo...

trar disputas que concernieran los poderes presidenciales, la situación era diferente. Considérese el siguiente artículo de la Constitución de 1967:
Art. 58 - En caso de urgencia o de interés público relevante, y siempre que no implique un aumento de los gastos del gobierno, el presidente de la República puede promulgar decretos con fuerza de ley en los siguientes temas:
I - seguridad nacional;
II - finanzas públicas.
Párrafo único - El decreto será inmediatamente vinculante. Des- pués de ser publicado en el boletín oficial, el Congreso lo aprobará o rechazará durante los siguientes 60 días.
El Congreso no puede enmendar el texto. Si, previo a esta fecha límite, no hay deliberación del Congreso, el texto del decreto se considerará aprobado. ${ }^{24}$

El artículo 58 confiere al presidente el poder de dictar decretos que inmediatamente adquieren "fuerza de ley", aunque estos decretos pueden ser rechazados ex post por el Congreso, tal como cualquier otra ley. Sin embargo, nada en el propio artículo 58 impide el control de constitucionalidad de los actos presidenciales basados en esta disposición. ${ }^{25}$ Además, establece límites claros a la legislación presidencial, como observara un constitucionalista en los años 1960: (i) debe existir "urgencia" e "interés público relevante" en la adopción del decreto-ley, (ii) el decreto-ley no puede elevar los gastos establecidos por el presupuesto anual, y (iii) la cuestión debe involucrar ya sea seguridad nacional (art. 58, I) o finanzas públicas (art. 58, II) (Ataliba, 1968).

Aun así, el STF leía en el artículo 58 una cláusula de "no justiciabilidad". En 1967, el presidente Castelo Branco promulgó el Decreto-Ley 322, cam-

${ }^{24}$ Todas las traducciones de los textos legales brasileros y de las decisiones judiciales son propias.

25 Como vimos, las cláusulas que establecían límites al ámbito del control de constitucionalidad de ciertas leyes y medidas adoptadas por el régimen solían encontrarse en los atos institucionais. Sin embargo, el artículo 58 es parte de la Constitución de 1967, que, aunque confería poderes generosos al presidente, no colocaba al ejercicio de tales poderes por encima del control de constitucionalidad. 
biando las reglas sobre alquiler de propiedades urbanas. El Decreto-Ley fue impugnado ante las cortes, y eventualmente llegó al STF. Una mayoría de jueces se unieron al ponente, el juez Aliomar Baleeiro, en declarar la inconstitucionalidad del decreto. Este fallo es frecuentemente celebrado como una muestra de independencia judicial bajo el régimen militar. De hecho, la decisión fue valiente, en cuanto anuló una medida legislativa del presidente-general que gobernaba. Sin embargo, el razonamiento de la decisión es mucho más deferente para con el poder ejecutivo que lo que sugeriría el resultado.

El juez Baleeiro estableció que los conceptos de "seguridad nacional" y "finanzas públicas", aun siendo amplias, no impiden el control constitucional solo por su vaguedad. ${ }^{26}$ Dado que estas preguntas involucraban la interpretación de las disposiciones constitucionales explícitas y detalladas sobre el tema de un tipo particular de proceso legislativo, no se trataba de una cuestión exclusivamente política.

El juez Baleeiro incluso sostuvo que no tocaba a los jueces brasileros revisar lo que el presidente había considerado "urgente" y "relevante":

La determinación de los casos de "urgencia" o "interés público relevante", mencionados en el Artículo 58 de la Constitución de 1967, tiene una naturaleza política y por consiguiente queda en manos de las decisiones discrecionales del presidente de la República acerca de su conveniencia y valor, excepto cuando el Congreso use su propia discrecionalidad para realizar una evaluación diferente. ${ }^{27}$

En otras palabras, el Decreto-Ley 322 fue declarado inconstitucional solo porque regular alquileres no era ni un asunto de finanzas públicas ni de seguridad nacional. Al mismo tiempo, sin embargo, la Corte determinó que no podía discutir qué significaban "urgencia" e "interés público

${ }^{26} \mathrm{RE}$ 62.731. “[...] El concepto de seguridad 'nacional' no es indeterminado ni vago, ni abierto a la discreción del presidente ni del Congreso. 'Seguridad Nacional' involucra todos los casos relacionados con la defensa de la integridad territorial, la independencia, sobrevivencia y paz interna del país, sus instituciones y sus valores materiales o morales, contra amenazas externas o internas, sean éstas reales e inmediatas o potenciales y remotas". 
La moderación judicial como legado constitucional autoritario: el Supremo...

relevante" en un determinado contexto. Esta decisión no necesariamente está "mal". El derecho constitucional brasilero, tal como lo entendía el STF en su momento, tradicionalmente había dejado muchos asuntos a la pura discrecionalidad presidencial, especialmente cuando no involucraban la violación de un derecho individual. ${ }^{28}$

Aún así, el juez Baleeiro escribió en su opinión que el régimen militar no había promulgado ninguna norma escrita que privara a la Corte de sus poderes de control de constitucionalidad, en el uso de los poderes del artículo 58. Era legalmente posible y plausible que hubiera decisiones menos deferentes. ${ }^{29}$ La Corte podría haber dicho, por ejemplo, que discutir qué es "urgente" y "relevante" corresponde en principio al ámbito de la decisión judicial, pero que había lugar para un margen de apreciación más amplio. Otra posibilidad (quizá incluso más plausible) hubiera sido decidir el caso sin articular una teoría tan completa del control de constitucionalidad de la legislación presidencial bajo el artículo 58.

Como evidencia de la plausibilidad de decidir el caso sobre bases más moderadas, podemos señalar los estudios de constitucionalistas circa 1967. Geraldo Ataliba, un respetado y conocido especialista que no era crítico del régimen militar, publicó en 1968 una monografía que se consagró luego como el comentario doctrinal clásico sobre el artículo 58. Este poder presidencial, escribió Ataliba, está explícitamente restringido por el texto constitucional en varias dimensiones - y todas estas restricciones pueden ser ejecutadas tanto por el Congreso como por el poder judicial (Ataliba, 1968, p. 27) - Más aún, Ataliba agrega que el poder judicial podría incluso no acordar con la valoración del Congreso sobre si en un determinado caso los requerimientos constitucionales para la promulgación de decretos-ley han sido cumplidos por el presidente (Ataliba, 1968, p. 29). Al discutir específicamente los términos "urgencia" e "interés público relevante", y al criticar la decisión del STF sobre el Decreto-Ley 322, Ataliba comentó:

${ }_{28}$ Para una doctrina clásica e influyente, véase Barbosa (1983 [1910]).

29 Debe señalarse que, en ese momento, el país aún no había ingresado al estadio más brutal de represión de disidentes políticos, que comenzó con la promulgación de AI - 5 en 1968. 
Antes de examinar la sustancia del Decreto-Ley, el Poder Judicial debe - en orden a determinar si su promulgación está dentro de la competencia excepcional del presidente de la República-fallar acerca de la existencia de un interés público relevante que requiriera esta medida extraordinaria, o la solidez de la declaración de urgencia (atendiendo a los hechos mencionados [por el presidente]) (Ataliba, 1968, pp. 28-29).

El hecho de que un miembro del establishment del derecho brasilero publicara un libro criticando una decisión del STF durante un período dictatorial, muestra que una decisión diferente (menos deferente) era posible legalmente. Más aún, debería aclararse que, en ese caso, el STF falló contra el gobierno. Como se mencionara anteriormente, esta decisión tuvo lugar antes de que la "línea dura" de la dictadura tomara el poder; si el STF se sentía lo suficientemente cómodo en ese ambiente político como para tomar la difícil decisión de fallar en contra del gobierno militar, entonces debiera haber sido más fácil encontrar espacio para un razonamiento diferente, menos deferente, a favor del mismo resultado.

El fallo del STF sobre el Decreto-Ley 322/1967 fue, en este sentido, un tipo extraño de decisión anti-Marbury vs. Madison: mientras que a corto plazo desafiaba al gobierno, a largo plazo proveía al régimen militar de poderes aumentados al crear explícitamente un ámbito de discrecionalidad presidencial cuasi absoluta, que no era requerida claramente por ninguna disposición del texto constitucional. Este escenario no sugiere una conducta puramente estratégica, sino, antes bien, señala la influencia de concepciones y opiniones judiciales sinceras, en el ámbito de las facultades legislativas presidenciales.

\subsection{Desmantelamiento judicial de pesos y contrapesos}

La matriz legal autoritaria que predominó antes de la democratización en Brasil reservó así un lugar importante para una discrecionalidad amplia en el uso de facultades legislativas por parte del Ejecutivo. Durante y después de la transición democrática, y a pesar de los cambios institucionales 
La moderación judicial como legado constitucional autoritario: el Supremo...

que trajo la nueva Constitución, este escenario pareció permanecer más o menos estable. Antes de que se promulgara la nueva Constitución (19851988), el primer presidente civil —el presidente José Sarney— gobernaba el país utilizando los poderes de legislación presidencial de 1967. Asimismo, en los diecisiete meses entre la promulgación de la Constitución de 1988 y el final de su mandato, Sarney promulgó 125 medidas provisórias. Este modelo de "activismo legislativo" presidencial no cambió cuando Fernando Collor tomó el lugar de Sarney. ${ }^{30}$ Durante la presidencia de Sarney, las medidas provisórias se transformaron respecto a lo que habían anticipado los redactores de la Constitución. Ya desde 1990, las medidas se habían transformado en un recurso presidencial para legislar de manera unilateral que (i) fue virtualmente inmune a la revisión por el poder judicial y (ii) podía ser renovado una y otra vez en caso de inacción del Congreso, más allá de la fecha de vencimiento prescrita por la Constitución. Sin embargo, las propiedades (i) y (ii) son precisamente la negación de los mecanismos establecidos por los creadores de la Constitución para asegurar que la medida provisória fuera compatible con el gobierno democrático. ¿Cómo fue posible este resultado, menos de dos años después de que la nueva constitución moderara explícitamente la legislación presidencial?

Parte de la respuesta puede encontrarse en la jurisprudencia del STF. En 1989, el presidente Sarney promulgó una medida provisória cambiando el código de procedimiento penal para incluir una autorización a la policía para requerir el arresto "temporario" y la custodia de un sospechoso o de un testigo de un posible crimen, si se consideraba necesario para la obtención de evidencia sensible. La Asociación Nacional de Abogados (ANA) presentó una demanda de control abstracto de constitucionalidad (ADI-MC 162) arguyendo que un cambio tan drástico en el procedimiento penal no podía ser considerado "urgente" y requería debates legislativos más extendidos. Esta fue la primera vez en la que se le solicitó al STF su interpretación de las condiciones de "necesidad" y "urgencia" del artículo 62.

${ }^{30}$ Da Ros (2008, pp. 145-146) argumenta que, una vez promulgada la Constitución de 1988, la función original de las medidas provisórias fue transformada en otra cosa, en tanto "la formulación de políticas desde el Ejecutivo transformó las medidas provisorias de instrumentos de legislación de emergencia, en actos de gobierno habituales". 
En ese momento, ocho de once jueces habían sido designados por el régimen militar saliente. El primer presidente civil, José Sarney, solo había designado tres jueces (Celso de Mello, Paulo Brossard, y Sepúlveda Pertence). Como era de esperar, esta corte mayormente "vieja" buscó continuidades jurisprudenciales a través del cambio de constituciones. En su decisión, la corte declaró que, en principio, dependía de los poderes políticos decidir qué contaba como "urgente" y "relevante" a los fines del artículo 62. El control de constitucionalidad de estos requisitos ante una medida provisória dada solamente podía suceder en casos extremos, pero la Corte no ofreció tests o estándares sobre cómo identificar un "caso extremo".

Sin embargo, aún más importante que lo que fue decidido fue cómo la Corte justificó su decisión. Escribiendo por la mayoría, el juez Moreira Alves trazó el pedigree del fallo directo hacia la opinión del juez Baleeiro en RE 62.739, que se discutió en profundidad en la sección previa de este artículo. ${ }^{31}$ En su voto por la mayoría, el juez Moreira Alves asevera que la interpretación de tales cláusulas "depende de las decisiones discrecionales sobre oportunidad o valor del presidente de la República, limitado por una decisión diferente e igualmente discrecional de parte del Congreso". Sin embargo, el juez Moreira Alves continúa diciendo que esto no debería entenderse como un poder absoluto - todos los abusos pueden y deben ser revisados por la Corte, tal como lo realizó finalmente el STF en el caso de 1967-:

Los conceptos de relevancia y urgencia a los que refiere el Artículo 62 de la Constitución, como condiciones necesarias para la promulgación de medidas provisórias, dependen en principio de las

31 "Esta Corte, en pleno, en su decisión del Recurso Extraordinário n.62.739, en que declaró inconstitucional, según la Constitución de 1967, el Decreto-Ley 322, por entender que regulaba materia extraña al concepto de seguridad nacional, se manifestó en el sentido de que 'la apreciación de los casos de urgencia' o de 'interés público relevante' al que se refiere el artículo 58 de la Constitución de 1967, asume carácter político, y queda en manos de la discrecionalidad de los juicios de oportunidad o de valor del Presidente de la República, salvo la posibilidad de apreciación contraria y también discrecional del Congreso" (RTJ44/54). Posteriormente, ese entendimiento fue seguido en RE 74.096 (RTJ 62/819) y en RE 75.953 (RDA 125/89). 
La moderación judicial como legado constitucional autoritario: el Supremo...

decisiones discrecionales sobre oportunidad o valor del Presidente, pero pueden ser sometidas a control de constitucionalidad en caso de exceso en el uso de esta facultad legislativa. Sin embargo, en este caso no se percibe este exceso de modo inmediato. ${ }^{32}$ (Las cursivas son propias).

Dos jueces - dos de los tres que habían sido designados luego de la transición democrática - presentaron opiniones disidentes considerando inconstitucional la medida. ${ }^{33}$ El principal argumento de quienes disentían era que había limitaciones temáticas implícitas sobre lo que podía ser regulado por una medida provisória, y las normativas sobre procedimiento criminal solo podían ser cambiadas a través procedimientos legislativos convencionales en el Congreso. Sobre la cuestión del alcance del control de medidas provisórias, los disidentes la ubican entre las garantías constitucionales clave contra el uso arbitrario de este poder excepcional por parte del presidente. ${ }^{34} \mathrm{El} \mathrm{juez} \mathrm{Celso} \mathrm{de} \mathrm{Mello} \mathrm{afirmó} \mathrm{que} \mathrm{la} \mathrm{concepción}$ pretransicional era incompatible con el esfuerzo transicional de limitar los "círculos de poder incontrolados" existentes. ${ }^{35}$ Con una lectura ligeramente

32 En p. 1. Véase en pp. 10-11 la opinión del juez Moreira Alves. Expone además que la posibilidad de controlar usos extremadamente errados también existe en Italia — donde, de acuerdo con la opinión de Moreira Alves, los constituyentes se inspiraron para las medidas provisórias - Pero mientras no haya "abuso de facultad de legislar" (esto es, uso excesivo del poder de legislar), la STF no tiene por qué controlar este aspecto de las medidas provisórias.

${ }^{33}$ Los jueces Sepúlveda Pertence y Celso de Mello. Cabe señalar que, al momento de escribir este artículo, el juez Celso de Mello aún formaba parte de la Suprema Corte.

34 Véase la opinión del juez Celso de Mello, pp. 15-16 (afirma que "no hay dudas de que las medidas provisorias [...] son un instrumento excepcional", y que "la promulgación de tales medidas por parte del Presidente son una derogación momentánea del principio de separación de poderes"; expresa que los constituyentes crearon varios controles para que esta facultad permaneciera controlada, tales como [i] el requerimiento de que el Congreso se reúna en una sesión extraordinaria; [ii] el requerimiento de que la medida provisional sea inmediatamente enviada al Congreso; [iii] la pérdida de fuerza de ley después de la fecha de expiración; [iv] la posibilidad de control de constitucionalidad).

35 Véase la opinión del juez Celso de Mello, p. 16 (en cuanto afirma que el presidente "es el árbitro inicial en relación a la conveniencia, la necesidad, utilidad y lo expeditivo de usar [las facultades de promulgar medidas provisorias], pero no el árbitro final. [...] Aceptar de antemano que no hay posibilidad de que el control de constitucionalidad de estas medidas quisiera decir una expansión ilimitada de los poderes presidenciales, lo cual sería incompatible 
diferente a la del juez Moreira Alves, el juez Sepulveda Pertenece felicitó a la mayoría por no tomar la vía fácil de importar la concepción de la separación de poderes y de la legislación presidencial "que fue construida bajo el viejo Estatuto", caracterizado por "un veto absoluto [...] de la posibilidad de examen judicial de los prerrequisitos discrecionales para emitir un decreto-ley". De acuerdo con Pertenece, "la influencia de los viejos precedentes podría resultar en la extensión al nuevo régimen, y especialmente en relación a las medidas provisórias", de la doctrina establecida por la Corte en la década de $1960 .{ }^{36}$ Según el disenso de Pertenece, entonces, la buena noticia era que el STF no se había dejado influenciar.

La interpretación del juez Pertenece acerca de la opinión mayoritaria hizo eco en muchos académicos, que señalaron una ruptura entre la concepción pre y postransicional del STF acerca de la justiciabilidad de las medidas provisórias de "urgencia" y "relevancia". ${ }^{37}$ En lugar de continuidad, esta interpretación identifica un cambio relativo (aunque modesto) en la comprensión por parte de la Corte. Antes de 1988, la Corte había descartado completamente la posibilidad de revisar este aspecto de las decisiones legislativas del presidente. Pero, bajo la nueva Constitución, y como bien apunta un académico, a pesar de "una cierta timidez", la Corte "no se apartó de la arena política por completo" (Da Ros, 2008).

Esta interpretación es problemática. Desde mi punto de vista, el juez Pertenece se equivocó al felicitar a la Corte por abandonar las comprensiones pretransicionales. Primero, la opinión mayoritaria del juez Alves está redactada de modo que vuelve difícil ver allí solo una superposición en la sustancia de las dos doctrinas: Alves dice que “esta Corte”, en 1967, ya había establecido la cuasi imposibilidad de revisión judicial de la interpretación

con nuestro sistema constitucional" y p.18 afirma que uno de los objetivos de la Constitución brasilera es "disminuir y eliminar progresivamente los círculos de inmunidad de poder".

36 Véase la opinión del juez Sepulveda Pertence.

37 Véase, por ejemplo, Da Ros (2008, p. 149): “Dado que hay una clara continuidad en las reglas que gobiernan la relación entre el Ejecutivo y el Legislativo entre los dos períodos [...], esto podría reforzar la inercia jurisprudencial, con la decisión de la corte de no intervenir en las actividades legislativas presidenciales. Sin embargo, esto no fue lo que sucedió, al menos si consideramos el caso que sentó precedente que avivó los primeros debates en el tema, dentro del STF, después de la promulgación de la nueva constitución". Para una evaluación diferente (y negativa) de la actuación de la corte en esta materia, véase Comparato (2001). 
La moderación judicial como legado constitucional autoritario: el Supremo...

presidencial y del Congreso de estas cláusulas. Segundo, no hay divergencia sustancial entre las doctrinas pretransicionales y postransicionales. En varios casos resueltos entre 1967 y 1989 (bajo la doctrina pretransicional), el STF había dejado claro que aceptaba (al menos en principio) la posibilidad de revisión judicial en casos extremos, tal como lo hizo el STF posterior a 1988. ${ }^{38} \mathrm{El}$ "cambio" sustancial entre las dos doctrinas supuestamente diferentes, entonces, parece sobrevalorado. Tercero, entre 1989 y 1998 el STF jamás anuló una medida provisória por falta de "urgencia" e “interés público relevante"; cuando la Corte finalmente anuló una, en 1998, la medida también fue considerada inconstitucional por muchos otros motivos, y pasaría otra década antes de que una medida fuese anulada solo porque no cumplía con los estándares de "urgencia" o "relevancia". 39 Este modelo de completa deferencia a las decisiones presidenciales sobre la "urgencia" también puede encontrarse en el orden preconstitucional, en relación con los decretos-lei.

Los tres factores aquí presentados son suficientes para establecer la continuidad entre las dos doctrinas de moderación judicial, en tres niveles diferentes:

(i) el nivel del precedente, en cuanto la nueva decisión es presentada como una reformulación de algo que "esta Corte" ya ha abordado y sobre lo cual ha fallado - la misma cuestión, decidida por una Corte que se presenta como la misma que la del régimen anterior-;

(ii) el nivel substantivo, en cuanto las dos decisiones establecen doctrinas de deferencia con estructuras, condiciones, y requerimientos perfectamente equivalentes: la revisión judicial de la interpretación

38 Véase, por ejemplo, RE 75935, una decisión unánime escrita por el mismo juez Baleeiro, quien articuló por primera vez la doctrina de la deferencia: "el control de constitucionalidad en esta instancia [de los requerimientos de los decretos-ley] deben ser excepcionales, sólo cuando el ejercicio de la discrecionalidad, alcanzando lo absurdo, linda con la arbitrariedad".

39 En ADIn 1753-2 (1998), la Suprema corte falló que era inconstitucional que una medida provisoria incrementara las ventajas procedimentales (esto es, fechas límites extendidas para presentar apelaciones) que se le garantizaban a fiscales y defensores públicos en los litigios. Pero, en ese caso, la Corte usó mayormente argumentos constitucionales (resultantes de la igualdad y el debido proceso legal), mientras que sumaba la falta de "urgencia" a las varias razones. 
del Ejecutivo de lo que es "urgente" y "relevante" no es posible, excepto cuando tal interpretación es claramente absurda; $y$

(iii) el nivel práctico, dado que la postura judicial producida por la aplicación de estas doctrinas fue clara e inequívocamente deferente para con la legislación presidencial durante un largo período de tiempo.

Esto significa que la misma Corte Suprema, al aplicar diferentes disposiciones constitucionales, en dos órdenes constitucionales diferentes e incompatibles, llegaron a resultados que eran equivalentes, a todos los fines prácticos relevantes. Esta continuidad es visible, no obstante las interpretaciones más optimistas del caso que sentó precedente en 1989 (tales como las del juez Pertenece). En las décadas siguientes, el STF mostró cierto grado de sensibilidad al aumento de demandas por un mayor control de constitucionalidad de las medidas provisórias. Durante los 90, la jurisprudencia de la Corte alternó entre dos patrones diferentes, a veces reafirmando la imposibilidad de revisión judicial, a veces recordando al poder político que tal revisión era posible en algunos casos extremos. ${ }^{40} \mathrm{En}$ cualquier caso, estos dos patrones siempre operaron en el espacio ambiguo entre deferencia en "casos normales" y control de constitucionalidad en "casos absurdos" - categorías que no fueron del todo explicadas, ejemplificadas o instanciadas por la Corte hasta mucho tiempo después-.

\section{3. ¿De "Provisoria" a "Permanente"?}

En la decisión de 1989 sobre la medida provisória de Sarney, el STF estableció una continuidad entre las medidas provisórias y los decreto-lei, con relación al alcance del control de constitucionalidad judicial sobre las interpretaciones presidenciales de "urgencia" y "relevancia". Al hacerlo, la Corte deshabilitó ampliamente uno de los dos conjuntos de garantías que habían sido creadas por la ANC para volver compatible la facultad legislativa presidencial con el gobierno democrático. Con el tiempo, la Corte procedió a deshabilitar el segundo conjunto de garantías. Como vimos, la fecha límite de 30 días 
La moderación judicial como legado constitucional autoritario: el Supremo...

establecida por el artículo 62 volvió realmente provisorias las medidas provisórias. Esta regla fue un rechazo explícito del sistema previo de legislación presidencial, en el cual, si el Congreso no decidía sobre un decreto-ley hasta 60 días después de su promulgación, el decreto-ley devenía permanente, como cualquier otra ley. El artículo 62 invertía el efecto de la inacción del Congreso - pasaba de la solidificación a la nulidad de la legislación presidencial- . Aun así, en una serie de decisiones de principios de los 90, el STF neutralizaba esta inversión crucial y deliberada del sistema previo.

Luego de la transición, algunos de los jueces de la Corte advertían el vínculo crucial entre medidas provisórias y la consolidación de un nuevo orden constitucional. En 1990, el presidente Collor intentó volver a promulgar una medida provisória que acababa de ser rechazada por el Congreso, y la cuestión fue llevada al STF a través de un proceso de control abstracto de constitucionalidad (ADI 293). Por decisión unánime, la Corte anuló la medida vuelta a promulgar, por motivos puramente procedimentales. La decisión también afirmaba que, en el nuevo orden constitucional, "la necesidad de manifestación Legislativa [sobre una medida provisória] no puede suprimirse o hacerse a un lado". ${ }^{41}$ Varios jueces enfatizaron la necesidad de aplicar los nuevos textos constitucionales a toda costa, aun cuando no fuese conveniente para el gobierno. Y la ementa de la decisión - un resumen de los puntos y argumentos principales de la opinión que prevaleció- aseguraba que "depende de la Corte Suprema garantizar la tarea eminente de asegurar que esta realidad [las normas fijadas por la Constitución] no sea desfigurada" ${ }^{42}$

No obstante la feroz retórica de aquella decisión temprana, la Corte pronto se encontró haciendo precisamente aquello contra lo que había advertido. Apenas dos semanas después, una nueva decisión del STF volvió completamente opcional la manifestación legislativa sobre medidas provisórias, a los fines prácticos. En ADI 295, se pidió que la Corte anulara una de las medidas provisórias clave del presidente Collor. Con un movimiento muy controversial, el gobierno había prohibido a todas las cortes inferiores y jueces otorgar medidas cautelares en contra de la medida económica más 
controversial de Collor - el congelamiento de los activos que la gente tenía en los bancos (incluso cajas de ahorro) a partir de cierto monto-.$-{ }^{43} \mathrm{Si}$ bien Collor no tenía mayoría estable en el Congreso, los líderes del partido que tenía el control de la Cámara de Diputados evitaron hacerse responsables de decidir sobre una medida tan osada. ${ }^{44}$ Si el plan de Collor fallaba, el Congreso podía recoger los beneficios de no haber aprobado el controversial congelamiento de activos; por otro lado, si la medida sí funcionaba contra la inflación, el Congreso aún podía reclamar crédito por colaborar con la estrategia presidencial. Mientras el Congreso adoptaba este enfoque de "esperar y ver", venció la fecha límite constitucional de los 30 días. En ese lapso, Collor volvió a promulgar cuatro veces la medida provisória original.

La Asociación Nacional de Abogados (ANA) presentó una demanda de control abstracto de constitucionalidad contra la prohibición de interdictos judiciales. Uno de los argumentos principales de la ANA fue puramente procedimental: sin importar la sustancia de esta medida, no se podía permitir al presidente volver a promulgarla antes de la fecha límite de los 30 días. El silencio del Congreso era simplemente una maniobra política, y no una interpretación válida de la Constitución, y dependía de la Corte hacer cumplir el procedimiento que los creadores de la constitución diseñaron al ubicar las medidas provisórias en un ámbito constitucional diferente al de los decretos-ley autoritarios. ${ }^{45}$

El juez ponente, juez Paulo Brossard, que había sido designado por el presidente Sarney, presentó el problema como una comparación sobre los modos en que ambos mecanismos - decretos-ley y medidas provisoriaslidiaban con la inacción del Congreso. Según Brossard, los dos mecanismos tenían lógicas incompatibles y mutuamente excluyentes. La inacción del Congreso llevaba a una aprobación tácita de los decretos-ley, mientras que significaba rechazo tácito cuando se trataba de medidas provisórias. Además, Brossard conectó este debate con los arreglos más amplios respecto de la separación de poderes, sobre lo cual observó: "en el régimen previo,

43 Véase Power (1998).

${ }^{44}$ Power, 1998.

45 Para una discusión profunda sobre el modo en que se moldearon diferentes regímenes de medidas provisorias, desde 1988, por interacciones (e incluso a veces acuerdos) entre los tres poderes del gobierno, véase Ribeiro y Muniz (2020). 
La moderación judicial como legado constitucional autoritario: el Supremo...

la expiración de la fecha límite favorecía al Ejecutivo; en nuestro régimen actual, favorece a la Legislatura". ${ }^{46} \mathrm{El}$ artículo 62 incentivaba fuertemente al presidente a hacer que el Congreso delibere acerca de medidas de emergencia. Brossard decía que esto, sin embargo, no dejaba al presidente desamparado ante un Congreso reticente, puesto que el ejecutivo podía pedir una deliberación "urgente" y expeditiva sobre un proyecto de ley. El sistema estaba diseñado para conducir a una decisión explícita que involucrara a los dos poderes, de modo tal que el Congreso debería compartir responsabilidad por cualquier medida provisoria que superara la fecha límite de los 30 días.

El juez que votó a continuación, el Juez Marco Aurélio de Mello (quien había sido recientemente nombrado por el mismo Fernando Collor), argumentó que la Constitución no contiene ninguna disposición que explícitamente prohíba la reemisión de medidas provisorias, aun si contiene normas similares sobre otras partes del proceso legislativo. Otros jueces observaron que rechazar un proyecto de ley es diferente a no decidir sobre el mismo, ya que factores contingentes pueden evitar que un proyecto que sí es apoyado por una mayoría sea efectivamente aprobado en un momento dado. ${ }^{47}$ Por ejemplo, durante ciertos momentos del año y del ciclo electoral, es difícil reunir voces en el Congreso, ya que los legisladores están ocupados con sus campañas en sus estados. En todo caso, poner la carga de tales factores de inacción-inducción en la agenda presidencial fue considerada una mala idea.

Al final, la posición favorable acerca de volver a promulgar medidas provisorias prevaleció. La opinión del juez Brossard sobresalió como la única voz disidente en este asunto, enfatizando cómo la transformación desde los decretos-ley hacia las medidas provisorias era parte de un proceso más amplio de separar el gobierno democrático de la normativa autoritaria. Esta decisión fue significativa para la separación de poderes en el nuevo orden constitucional. Hasta comienzos de los años 2000, la política brasileña estaba dominada por la práctica recurrente de reemisión de medidas provisorias, por parte de diferentes gobiernos. A pesar de la constante crítica por parte de la academia, desde la década de 1990 una gran parte del derecho brasileño no había sido sujeta a decisión explícita

${ }^{46}$ ADI 295/90, Opinión del Juez Paulo Brossard, p. 7.

${ }^{47}$ Cf. Opinión del juez Sepulveda Pertence. 
del Congreso. ${ }^{48}$ Entre 1988 y 2001, el Congreso no rechazó ninguna medida provisoria - y el 14\% de todas las medidas promulgadas en ese período aún pasaban el Congreso (Abramovay, 2011, pp. 75-78)_. Esta información no es sorprendente. En la configuración institucional creada por el STF, el presidente siempre podía volver a promulgar una medida provisoria clave antes de su fecha de vencimiento, reconfigurando la duración del proyecto sin que el Congreso tuviera que pronunciarse sobre ello. ${ }^{49}$

En 2001, una enmienda constitucional cambió este estado de cosas. La Enmienda Constitucional n. ${ }^{\circ} 32$ reescribió y expandió el artículo 62. Entre otros varios cambios (incluidas limitaciones explícitas sobre la reemisión de medidas provisorias), EC 32/2001 estableció que las medidas provisorias podían volver a promulgarse una única vez. No obstante, considérese el escenario previo a esta enmienda. Tal como se discutiera previamente, recién en 1998 el STF finalmente consideró que una medida provisoria no era "urgente" y/o de "interés público relevante". En la práctica, entonces, en los 90 Brasil fue un escenario en el cual la legislación presidencial unilateral estaba libre de los controles de constitucionalidad y del Congreso ex post - esto es, libre de las limitaciones que se suponía que hacían diferir a las medidas provisorias de los decretos-ley, y por ende las harían más compatibles con el nuevo régimen democrático-. La Constitución intentó crear un proceso obligatorio de diálogo entre poderes para cada medida provisoria. Aún si el presidente daba el primer paso, cada poder tenía que hacerse responsable de confirmar la legislación resultante (Abramovay, 2011, p. 69). Los dos casos del STF discutidos previamente en este trabajo vuelven opcional el diálogo institucional que los constituyentes intentaron establecer como obligatorio.

A fin de esclarecer la comparación, en la tabla siguiente (figura 2) se presentan los aspectos relevantes de cada mecanismo (decreto-lei y medida provisória), distinguiendo entre cuatro regímenes diferentes. El último régimen representa los cambios implementados por la Enmienda consti-

48 Para una reseña bibliográfica, véase Abramovay (2011, pp. 69-70).

49 Abramovay (2011, pp. 75-78). Más allá de la mera reemisión de una medida provisoria dada, también hubo casos en los que las medidas "reemitidas" incluían cambios significativos respecto del texto original. 
La moderación judicial como legado constitucional autoritario: el Supremo...

tucional n. ${ }^{\circ}$ 32, adoptada en el año 2001. Tal como se mencionó, uno de sus rasgos más importantes fue la creación del límite de una única repromulagación de una medida provisoria. En este sentido, la Enmienda 32/2001 resolvió un problema creado por el propio STF, cuando rediseñó el sistema de las facultades legislativas presidenciales en el Brasil postransicional. En este sentido, la Constitución de 1988 no necesitó prohibir explícitamente la reemisión de medidas provisorias. Como había subrayado el juez Brossard, la cuestión principal es trazar la línea entre formas autoritarias y democráticas de legislación presidencial. Aun sin el beneficio de la retrospección, y sin saber cómo la práctica evolucionaría en la arena política de la década siguiente, la comparación directa de Brossard entre los dos mecanismos - medidas provisórias y decretos-leis - fue suficiente para mostrar que la fecha de expiración era crucial para limitar el poder presidencial.

Figura 2: Instrumentos de Legislación Presidencial en Brasil, 1964-2001

\begin{tabular}{|c|c|c|c|c|}
\hline & $\begin{array}{c}\text { "Decreto- } \\
\text { Lei" } \\
(1964-1988)\end{array}$ & $\begin{array}{l}\text { "Medida Provi- } \\
\text { sória I" } \\
\text { (texto original } \\
\text { de 1988) }\end{array}$ & $\begin{array}{c}\text { "MP II" } \\
\text { (interpretada } \\
\text { por la STF, } \\
\text { 1989-2001) }\end{array}$ & $\begin{array}{c}\text { “MP III” (luego } \\
\text { de la Enmienda } \\
\text { Constitucional 2001) }\end{array}$ \\
\hline $\begin{array}{l}\text { Fecha de } \\
\text { vencimiento }\end{array}$ & 60 días & 30 días & 30 días & $\begin{array}{c}60 \text { días, renovable por } \\
\text { otros } 60 \text { días }\end{array}$ \\
\hline $\begin{array}{l}\text { Consecuen- } \\
\text { cias del } \\
\text { vencimiento }\end{array}$ & $\begin{array}{c}\text { Mantiene la } \\
\text { fuerza legal; } \\
\text { aprobación } \\
\text { tácita del } \\
\text { Congreso }\end{array}$ & $\begin{array}{l}\text { Pierde fuerza } \\
\text { legal. }\end{array}$ & $\begin{array}{l}\text { Pierde fuerza } \\
\text { legal. }\end{array}$ & $\begin{array}{l}\text { Después de } 120 \text { días } \\
\text { pierde fuerza legal; } \\
\text { después de } 45 \text { días, } \\
\text { "cierra" la agenda del } \\
\text { Congreso hasta que se } \\
\text { tome una decisión. }\end{array}$ \\
\hline $\begin{array}{l}\text { Posibilidad } \\
\text { de volver a } \\
\text { promulgar }\end{array}$ & $\begin{array}{c}\text { No } \\
\text { corresponde }\end{array}$ & $\begin{array}{l}\text { No se } \\
\text { menciona la } \\
\text { reemisión. }\end{array}$ & $\begin{array}{l}\text { Se permite } \\
\text { volver a } \\
\text { promulgar. }\end{array}$ & $\begin{array}{l}\text { Puede renovarse una } \\
\text { vez. No puede volver a } \\
\text { promulgarse. }\end{array}$ \\
\hline
\end{tabular}

Fuente: el autor. 


\section{Conclusión}

La nueva Constitución de 1988 designó un sistema de toma de decisiones políticas con muchos pesos y contrapesos, en el cual la Suprema Corte estaba explícitamente empoderada para jugar un rol central. Sin embargo, contrariamente a las expectativas de políticos, activistas y académicos del derecho, la Suprema Corte brasileña postransicional rechazó esta invitación explícita. En una serie de decisiones tomadas menos de dos años después de la promulgación de la Constitución de 1988, la Corte cambió sustancialmente normas constitucionales que habían sido deliberadamente instituidas por la NCA para marcar la diferencia entre los viejos y los nuevos arreglos o diseños sobre la separación de poderes respecto de la legislación presidencial. En lugar de redimir la promesa de transformación que estaba contenida en el nuevo texto constitucional, la Corte transformó rápidamente al texto en algo mucho más cercano en esencia al orden constitucional previo. La corte puso a debatir las interpretaciones predemocráticas y de la vieja Constitución, sobre el significado de la nueva Constitución. Este proceso de mantener viva la jurisprudencia pretransicional se dirigió a cuestiones de la nueva estructura constitucional que habían sido deliberadamente designadas para marcar una ruptura con el viejo orden constitucional. A través de interpretación judicial, el sistema de medidas provisorias diseñado por el nuevo texto constitucional fue finalmente reelaborado en algo notablemente similar a los infames decretos-ley — la forma de legislación presidencial tan característica de la dictadura brasileña, que la ANC se había comprometido a abandonar-.

En regímenes previos de Brasil, el presidente había estado tradicionalmente dotado con vastas facultades legislativas. Sin embargo, este empoderamiento no fue simplemente el resultado de textos constitucionales autoritarios. Estuvo parcialmente moldeado y acrecentado por interpretaciones judiciales, adoptadas por jueces de la Corte Suprema en fallos sobre los límites de la legislación presidencial en contextos políticos autoritarios. Así como los jueces de la Corte Suprema brasileña permanecieron inmutables durante la transición, la Corte tendía a ver continuidad, en su propia senda institucional, entre la dictadura militar y la nueva democracia. Esta conti- 
La moderación judicial como legado constitucional autoritario: el Supremo...

nuidad fue reafirmada en la interpretación de las nuevas disposiciones constitucionales que dieron forma a las facultades legislativas presidenciales. ${ }^{50}$

Así, la Corte postransicional leyó la nueva Constitución con viejos lentes $^{51}$. Al hacerlo, muestra cómo variables legales específicas ayudan a explicar la conducta judicial en las nuevas democracias. Mientras que la moderación judicial en democracias en consolidación es quizás esperable desde un punto de vista de conducta estratégica, en este artículo he subrayado la relevancia, en el caso brasileño, de la concepción legal preconstitucional sobre la toma de decisiones judicial. Tales concepciones legales pueden influenciar la conducta judicial más allá de los cálculos estratégicos, siempre que puedan expresar y moldear creencias judiciales sinceras acerca del alcance apropiado de la revisión judicial, y del rol adecuado de su institución en relación con los demás poderes. Además, el caso brasileño muestra que el legado de las concepciones judiciales tradicionales puede incluso superar nuevos textos constitucionales - aun cuando claramente empoderan a las cortes a revisar los otros poderes del gobierno-, moldeando de modos perdurables la separación de poderes.

\section{Bibliografía}

Abramovay, P. (2011). Medidas Provisórias e Separação de Poderes. Rio de Janeiro: FGV.

Ackerman, B. (2000). The New Separation of Powers. Harvard Law Review, 113(3), 633-727.

Ackerman, B. (1997). The Rise of World Constitutionalism. Virginia Law Review, 83(4), 771-797.

Arantes, R. (1997). Judiciário e Política no Brasil. São Paulo: Editora Sumaré/FAPESP/EDUC.

50 Para una discusión más amplia acerca de las implicancias constitucionales de tener los mismos jueces y/o la misma Suprema Corte durante la transición de dictadura a democracia, véase Arguelhes (2014).

${ }^{51}$ Un constitucionalista ha denominado a este modus operandi "interpretación retrospectiva" - la interpretación judicial de textos legales nuevos para volverlos lo más parecidos posibles a las leyes anteriores (Barroso, 1996, p. 67). 
Arguelhes, D. W. (2014). Old Courts, New Beginnings: judicial continuity and constitutional transformation in Argentiana and Brazil (Tesis Doctoral, inédito). Yale Law School: United States.

Arguelhes, D. W. y Prado, M. M. (2019). 'Resistance by Interpretation': Supreme Court Justices as Counter-Reformers to Constitutional Changes in Brazil in the 90s". En R. Albert, C. Bernal y J. Z. Benvindo (eds.). Constitutional Change and Transformation in Latin America (pp. 167-188). Oxford: Hart Publishing.

Arguelhes, D. W. y Süssekind, E. P. (2018). Building judicial power in Latin America: opposition strategies and the lessons of the Brazilian case. Revista Uruguaya de Ciencia Politica [online], 27(1), 175-196.

Arguelhes, D. W. y Ribeiro, L. M. (2018). 'The Court, it is I'? Individual judicial powers in the Brazilian Supreme Court and their implications for constitutional theory. Global Constitutionalism, 7(2), 236-262.

Ataliba, G. (1968). Decreto-Lei na Constituição de 1967. São Paulo: Revista dos Tribunais.

Barbosa, R. (1983[1910]). O Direito do Amazonas ao Acre Setentrional. Rio de Janeiro: Fundação Casa de Rui Barbosa.

Barroso, L. R. (1996). Interpretação e aplicação da constituição: fundamentos de uma dogmática constitucional transformadora. São Paulo: Saraiva.

Brinks, D. (2011). Faithful Servants of the Regime: The Brazilian Court's Role under the 1988 Constitution. En G. Helmke y J. Rios-Figueroa, J. (eds.). Courts in Latin America (pp. 128-153). Cambridge: Cambridge University Press.

Carey, J. M. y Shugart, M. S. (1998). Calling out the Tanks or Filling out the Forms? En Carey, J. M. y Shugart, M. S. (eds.). Executive Decree Authority (pp. 1-30). Cambridge: Cambridge University Press.

Carey, J. M. y Shugart, M. S. (1992). Presidents and Assemblies: Constitutional Design and Electoral Systems. Cambridge: Cambridge University Press.

Carvalho, A. D. Z. (2017). Entre o dever da toga e o apoio à farda: Independência judicial e imparcialidade no STF durante o regime militar. Revista Braileira de Ciências Sociais, 32(94), 1-22. 
La moderación judicial como legado constitucional autoritario: el Supremo...

Cheibub, J. A., Elkins, Z. y Ginsburg, T. (2011). Latin American Presidentialism in Comparative and Historical Perspective. University of Chicago Public Law \& Legal Theory Working Papers n. 361, 89, 2011. Comella, V. F. (2003). The consequences of centralizing constitutional review in a special court: some thoughts on judicial activism. Texas Law Review, 82.

Comparato, F. K. (2001). A questão política nas medidas provisórias: um estudo de caso. Boletim dos Procuradores da República, 3.

Da Ros, L. (2008). Poder de Decreto e Accountability Horizontal: Dinâmica Institucional dos Três Poderes e Medidas Provisórias no Brasil pós1988. Revista de Sociología Política, 16(30), 131-149.

Figueiredo, A. y Limongi, F. (1999). Executivo e Legislativo na Nova Ordem Constitucional, Rio de Janeiro, FGV.

Gargarella, R. (2012). Latin American constitutionalism, 1810-2010: the engine room of the Constitution. Oxford: University Press.

Ginsburg, T. (2011). Judicial Review in New Democracies. Cambridge: Cambridge University Press.

Kapiszewski, D. (2011). Power Broker, Policy Maker, or Rights Protector. En G. Helmke y J. Ríos-Figueroa (eds.). Courts in Latin America (pp. 154-186). Cambridge, Cambridge University Press.

Kapiszewski, D. (2012). High courts and economic governance in Argentina and Brazil. Cambridge University Press.

Limongi, F. (2008). O Poder Executivo na Constituição de 1988. En R. G. Oliven, M. Ridenti y Brandão, G. M. (orgs.). A Constituição de 1988 na Vida Brasileira. São Paulo: Aderaldo \& Rothschild Editores.

Loveman, B. (1993). The Constitution of Tyranny: Regimes of Exception in Spanish America. Pittsburgh: University of Pittsburgh Press.

Lynch, C. (2012). O Caminho para Washington passa por Buenos Aires: A recepção do conceito argentino do estado de sítio e seu papel na construção da República brasileira (1890-1898). Revista Brasileira de Ciências Sociais, 27(78), 149-169.

Melo, M. A. y Pereira, C. (2012). Making Brazil work: checking the president in a multiparty system. Springer. 
Nino, C. S. (1992). Fundamentos de Derecho Constitucional: Análisis filosófico, jurídico y politológico de la práctica constitucional. Argentina: Editorial Astrea.

Pereira, A. W. (2005). Political (In)Justice: Authoritarianism and the Rule of Law in Brazil. Chile y Argentina, Pittsburgh: University of Pittsburgh Press.

Pilatti, A. (1999). O processo legislativo na constituição de 1988. En M. Camargo (ed.), 1988-1998: uma década de constituição, Rio de Janeiro: Lumen Juris.

Power, T. (1998). The Pen is Mightier than the Congress: Presidential Decree Power in Brazil. En J. M. Carey y M. S. Shugart (eds.). Executive Decree Authority. Cambridge: Cambridge University Press.

Ribeiro, L. M. y Muniz, M. N. (2020). Imaginação, Transgressão e Formalização: ações do Congresso e do STF na definição de regras de tramitação de medidas provisórias. Revista Estudos Institucionais, 6(1), 155-183.

Rosevear, E. (2018). Social Rights Interpretation in Brazil and in South Africa. Revista de Investigações Constitucionais [online], 5(3), 149-183. Santos, F. (2003). O Poder Legislativo no Presidencialismo de Coalizão- Belo Horizonte: UFMG.

Vasconcelos, N. P. (2020). Solução do problema ou problema da solução? STF, CNJ e a judicialização da saúde. Revista Estudos Institucionais, 6(1), 83-108. 